\title{
DEGRADAÇÃO NATURAL DE TORAS DE CINCO ESPÉCIES FLORESTAIS EM DOIS AMBIENTES
}

\author{
Henrique Trevisan*, Felipe Marauê Tieppo Marques**, Acacio Geraldo de Carvalho*** \\ *Eng. Florestal, M.Sc., Depto. de Produtos Florestais, UFRRJ - hentrevisan@gmail.com \\ **Acadêmico de Engenharia Florestal, UFRRJ - marauetieppo@yahoo.com.br \\ ***Eng. Florestal, Dr., Depto. de Produtos Florestais, UFRRJ - acacio@ufrrj.br \\ Recebido para publicação: 20/03/2007 - Aceito para publicação: 16/07/2007
}

\begin{abstract}
Resumo
Este trabalho teve como objetivo avaliar a degradação natural de toras recém-abatidas em dois ambientes, bem como registrar a ocorrência de térmitas e coleobrocas nas respectivas toras e ambientes. As espécies utilizadas foram, Eucalyptus urophylla S T Blake, "eucalipto" (Myrtaceae), Melia azedarach L., "cinamomo" (Meliaceae), Lophantera lactescens Ducke, "lanterneira" (Malpighiaceae), Pinus elliottii Engelm, "pinus" (Pinaceae), Inga marginata Willd, "ingá" (Mimosaceae). O experimento foi realizado em dois campos de apodrecimento, um dentro de uma floresta secundária e outro num pasto de gramíneas. Adotou-se um sistema de classificação no qual, conforme o nível de deterioração da tora, notas foram atribuídas, fornecendo base para o cálculo do índice de deterioração. As coleobrocas e as térmitas foram coletadas e enviadas para identificação. Registraram-se $56,6 \%$ de toras com a presença de térmitas no campo de dentro da mata, sendo as espécies ocorrentes: Nasutitermes minor (HOLMGREN, 1906), Nasutitermes jaraguae (HOLMGREN, 1910) e Heterotermes longiceps (SNYDER, 1924). No campo a céu aberto, foram registrados $20 \%$ das toras com a presença de térmitas, de uma única espécie, $H$. longiceps. Tanto no campo de apodrecimento de dentro da mata como no que foi montado a céu aberto, as toras menos degradadas foram M. azedarach e L. lactescens.

Palavras-chave: Deterioração; madeira; campo de apodrecimento.
\end{abstract}

\begin{abstract}
Natural degradation of logs from five forest species in two environments. This research had as objective to evaluate the natural degradation of a sample of a timber recently felled down, in two environments, as well as to register the occurrence of termites and beetles in the respective samples and environments. The searched species were, Eucalyptus urophylla S T Blake (Myrtaceae), Melia azedarach L. (Meliaceae), Lophantera lactescens Ducke, (Malpighiaceae), Pinus elliottii Engelm (Pinaceae), Inga marginata Willd (Mimosaceae). The experiment was accomplished in two rotten fields, one inside of a secondary forest and another one a gramineas pasture. We enrolled $56,6 \%$ of the sample with the presence of termites in the field within the forest, and the identified species were: Nasutitermes minor (HOMGREN, 1906), Nasutitermes jaraguae (SNYDER, 1924) and Heterotermes longiceps (SNYDER, 1924). In the open field it was registered $20 \%$ of the sample the shaft with the presence of termites, with only occurrence of only one species, H. longiceps. Were that one less deteriorated as inside the forest as in the open field: M. azedarach and L. lactescens.

Keywords: Deterioration; wood; rotten field; samples from.
\end{abstract}

\section{INTRODUÇÃO}

Segundo Aprile et al. (1999), a madeira encontra-se entre os materiais biológicos de mais difícil decomposição, devido à sua estrutura anatômica e à presença de grandes quantidades de substâncias recalcitrantes, como a lignina, além de outros compostos do metabolismo secundário. Sabe-se que a decomposição de materiais biológicos depende de uma série de fatores bióticos e abióticos, tais como as condições climáticas, a composição da comunidade decompositora, sua afinidade com o substrato e as características físicas e químicas do material a ser decomposto (SWIFT et al., 1979). 
Os agentes degradadores da madeira podem ser bióticos ou abióticos, sendo os primeiros os mais relevantes, por serem mais efetivos no processo de degradação. Nesse grupo encontram-se insetos, fungos, bactérias, algas e xilófagos marinhos. Já para os fatores abióticos, pode-se citar a ação das chuvas, dos ventos e da radiação solar.

A madeira está sujeita ao ataque de insetos, desde a árvore viva até aquela em condições de serviço, devido aos seus constituintes serem de origem orgânica, que os insetos utilizam como alimento ou substrato para reprodução ou moradia, sendo as principais ordens que a atacam a Isoptera (cupins), a Coleoptera (coleobrocas) e com menor importância a Hymenoptera (vespas e formigas).

Os cupins são insetos sociais, que vivem em colônias cujos indivíduos são divididos em castas com funções definidas: reprodução, trabalho e defesa da colônia. De modo geral, as espécies que atacam a madeira podem ser divididas em subterrâneas e de madeira seca. Segundo Richardson (1993), dentre os insetos xilófagos, são os mais severos agentes destruidores da madeira.

De acordo com Oliveira et al. (1986), as brocas, como também outros organismos xilófagos, têm seus hábitos alimentares estreitamente relacionados com o teor de umidade da madeira. De modo geral, o ataque pode ocorrer sob as seguintes condições: madeira com teor de umidade abaixo de 30\% é atacada por Anobiidae e Lyctidae; madeira em fase de secagem é atacada por Bostrichidae; árvores recémabatidas, ainda com alto teor de umidade e liberando substâncias químicas, atraem mais intensamente insetos das famílias Scolytidae e Platypodidae, embora ambas também sejam relatadas atacando árvores vivas; por fim, há uma faixa que compreende desde árvores vivas até troncos em adiantada decomposição, que normalmente sofre ataques de Cerambycidae. Com relação a Bostrichidae, o ataque também ocorre em madeira com baixo teor de umidade, como relatado por Matoski; Rocha (2006), que registraram Dinoderus minutus Fabricius (1775) atacando lâminas torneadas de Ceiba pentandra (L.) Gaertn, conhecida popularmente como sumaúma.

Os besouros das famílias Scolytidae, Bostrichidae, Platypodidae e Cerambycidae talvez sejam os grupos mais importantes. As coleobrocas da família Scolytidae e Platypodidae têm papel fundamental no processo de deterioração, pois perfuram galerias para nidificação em várias partes do tronco, essencialmente na madeira de árvores recém-abatidas ou debilitadas, que ainda estejam em processo de fermentação da seiva, liberando voláteis químicos atrativos a esses insetos (SIMEONE, 1965; FURNISS, CAROLIN, 1977). De tamanho comumente bastante reduzido, essas galerias, restritas à casca no caso das espécies fleófagas e profundas no lenho no caso das xilomicetófagas (besouros da ambrósia), podem ser consideradas portas de entrada para fungos biodeterioradores, sendo sítios potenciais para desenvolvimento de organismos, simbiontes ou não, responsáveis pela aceleração da degradação do material.

A atuação dos fungos na degradação da madeira também é intensa, segundo Sgai (2000). Os fungos destruidores mudam as propriedades físicas e químicas das paredes das células ou das cavidades celulares, chamadas traqueídeos, afetando seriamente a resistência da madeira. Esses fungos são os que produzem a decomposição da madeira. Quase todos atacam tão logo a árvore tenha sido cortada ou logo que ela tenha caído. Segundo Paes et al. (2001), os fungos xilófagos que causam mudanças na composição química da madeira são classificados em fungos de podridão-branca, de podridão-parda e de podridão-mole. A lignina é apenas ligeiramente degradada pelos fungos de podridão-parda e, mais intensamente, pelos fungos de podridão-branca e de podridão-mole.

É conhecido que o tipo de ambiente influencia na ocorrência dos organismos xilófagos, bem como na atuação dos fatores abióticos e no processo de decomposição da madeira. Nesse sentido, Cavalcante (1985) afirma que o comportamento da mesma madeira pode ser diferente em dois ambientes distintos, porque cada qual apresentará condições características de, por exemplo, umidade, insolação, aeração, temperatura etc. Esses fatores têm atuação sobre a madeira, determinando sua durabilidade.

Os estudos que pretendem avaliar a degradação da madeira, segundo Trevisan et al. (2007), devem envolver áreas distintas do conhecimento. Entre elas, podem ser citadas a entomologia, a micologia, a fisiologia vegetal e a tecnologia da madeira, sendo de extrema importância o sinergismo entre elas, para que o processo de degradação seja compreendido de forma integral, gerando uma base de dados sobre o comportamento dos organismos xilófagos, seja nas interações ecológicas entre eles, seja na interação com a própria madeira estudada.

A elucidação desses processos pode nortear o uso desse material, no sentido de indicar madeiras apropriadas a cada ambiente. Portanto, o conhecimento do potencial intrínseco a cada espécie florestal, bem como a dinâmica dos organismos xilófagos em dado ambiente, pode evitar o desperdício ocasionado pelo colapso de estruturas construídas com madeira inadequada. 
Este trabalho teve como objetivo avaliar a degradação de toras recém-abatidas de cinco espécies florestais em dois ambientes, bem como registrar a ocorrência de coleobrocas e térmitas nas respectivas toras e ambientes.

\section{MATERIAL E MÉTODOS}

\section{Espécies arbóreas}

A madeira utilizada neste trabalho foi obtida em árvores cultivadas no campus da UFRRJ (Universidade Federal Rural do Rio de Janeiro) e na Floresta Nacional Mário Xavier, em Seropédica (RJ). As espécies utilizadas foram: Eucalyptus urophylla S T Blake, "eucalipto" (Myrtaceae), Melia azedarach L., "cinamomo" (Meliaceae), Lophantera lactescens Ducke, "lanterneira" (Malpighiaceae), Pinus elliottii Engelm, "pinus" (Pinaceae), e Inga marginata Willd, "ingá” (Mimosaceae). A madeira de eucalipto é proveniente de um plantio homogêneo de 7 anos, e a de Pinus, de um plantio de 11 anos. As demais madeiras são oriundas de árvores de mesma idade, pois se trata de plantios homogêneos, mas de idade desconhecida.

\section{Escolha, padronização das toras e montagem dos blocos}

A Floresta Nacional Mário Xavier foi o local escolhido para o estabelecimento dos experimentos. Ambos foram instalados em solo com características homogêneas.

Dentro do contexto de que madeiras de uma mesma espécie florestal podem ter desempenho diferente por questões bióticas e abióticas do sítio onde estão sendo utilizadas ou avaliadas em sua durabilidade natural, foram montados dois campos de apodrecimento: um deles, em uma área em regeneração natural que constitui uma floresta secundária, e o outro em uma área de pastagem. Este último foi protegido com arame farpado para evitar a interferência de animais. Ambos forneceram dados sobre a degradação e a ação de degradadores em tais ambientes, uma vez que possuem características edafoclimáticas diferenciadas.

Em cada campo foi instalado um termômetro, devidamente protegido da insolação e da precipitação, para obtenção diária das temperaturas máxima e mínima.

De cada espécie foram utilizadas quatorze toras, sete para cada campo de apodrecimento, sendo que uma tora, em cada ambiente, foi destinada à retirada de sub-amostras, para coleta das coleobrocas. As toras mediam 1,5 $\mathrm{m}$ de comprimento e entre 0,2 e $0,3 \mathrm{~m}$ de circunferência, conforme metodologia proposta por Trevisan et al. (2003), com máxima uniformidade e sem defeitos na madeira, seguindo recomendações de Lopez; Milano (1986).

Imediatamente após a coleta, em 18 de agosto de 2004, as toras foram dispostas nas áreas experimentais divididas em seis blocos, com cinco amostras por bloco, para cada campo de apodrecimento. Foi realizado um sorteio para a definição da disposição das amostras dentro do bloco, sendo esta utilizada para todos os blocos. O espaçamento foi de 1,0 m entre amostras e 1,5 m entre blocos (Figura 1). As amostras foram enterradas verticalmente no solo a uma profundidade de $0,3 \mathrm{~m}$.

\section{Coleta das coleobrocas e quantificação dos danos}

Uma amostra de cada espécie foi instalada a uma distância de $2 \mathrm{~m}$ ao longo dos blocos, ambas também enterradas verticalmente a $0,3 \mathrm{~m}$ de profundidade, nos dois experimentos, das quais foram retiradas, com o auxílio de motosserra, sub-amostras de $20 \mathrm{~cm}$, quinzenalmente, durante 12 semanas, iniciando-se a partir do primeiro registro do ataque das coleobrocas, registro esse feito em inspeções diárias após a montagem dos experimentos. Após a coleta, as sub-amostras foram acondicionadas em sacos plásticos de polietileno e etiquetados, para posterior avaliação em laboratório. As sub-amostras foram desdobradas, no laboratório, com o auxílio de formão, martelo e estiletes, para coleta dos adultos das coleobrocas, que foram acondicionados em frascos com etanol a 70\% e etiquetados por experimento, espécie e bloco, para posterior identificação pela equipe do prof. Dr. Carlos A. H. Flechtmanm, da faculdade de Engenharia da Unesp (Universidade Estadual Paulista) de Ilha Solteira.

\section{Avaliação da durabilidade das toras e ocorrência de térmitas}

Uma avaliação final de campo, aos 12 meses, foi realizada com um leve movimento circular da tora quando ainda no solo, para verificar se a resistência foi reduzida a tal ponto de provocar a sua quebra. As demais avaliações foram feitas no Laboratório de Entomologia Florestal do Departamento de Produtos Florestais, Instituto de Florestas, UFRRJ, onde o nível de degradação foi classificado segundo um sistema 
de notas relacionado ao estado fitossanitário da madeira, conforme recomendações propostas por Lepage (1970) e adaptadas por Trevisan et al. (2003), para testes de campo com toras em contato com o solo (Tabela 1).

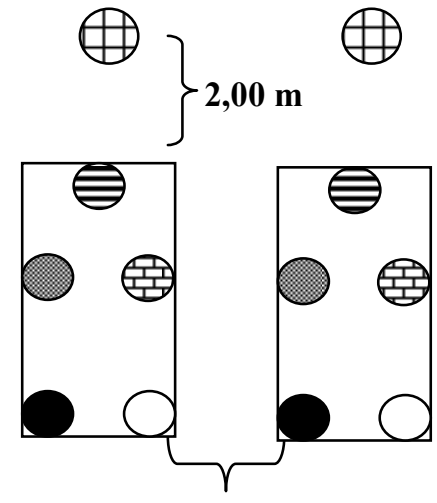

$1,50 \mathrm{~m}$

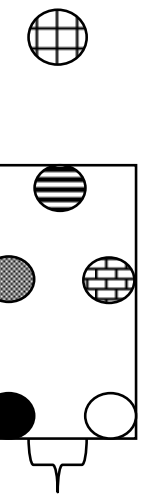

$1,00 \mathrm{~m}$
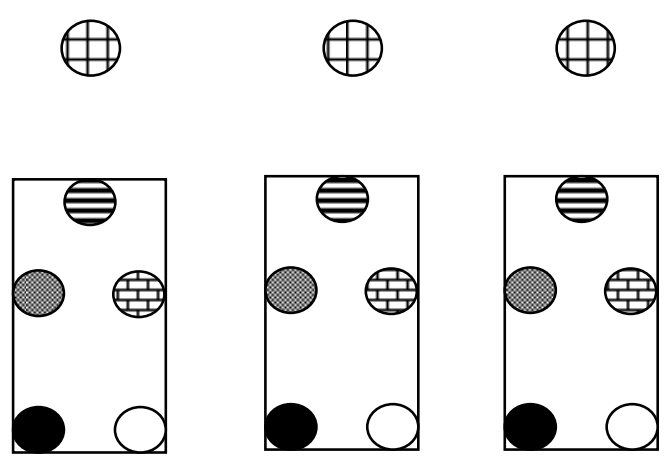
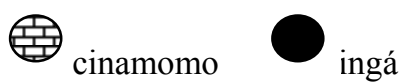
lanterneira

Figura 1. Croqui dos campos experimentais.

Figure 1. Outline of the experimental fields.

O índice de deterioração foi admitido para estabelecer o estado médio de cada amostra dentro de cada bloco. Ao final, foram somados os índices de deterioração para cada espécie, cujo valor foi dividido pelo número de amostras por espécie (seis), obtendo-se o índice de deterioração médio. Também foram observadas (1) a consistência da madeira, através de uma leve pressão com uma chave de fenda, e (2) a presença de rachaduras longitudinais no corpo da amostra. Os dois primeiros parâmetros foram avaliados tanto na parte aérea quanto na parte subterrânea da amostra, separadamente, conforme metodologia proposta por Trevisan et al. (2003).

Os espécimes de térmitas coletados nas amostras foram etiquetados e acondicionados em álcool $70 \%$ e enviados para o prof. Dr. Reginaldo Constantino, do Departamento de Zoologia da Universidade de Brasília, para identificação taxonômica.

Tabela 1. Classificação do nível de degradação das madeiras em contato com o solo (LEPAGE, 1970).

Table 1. Classification of the degradation level of wood in contact with the soil (LEPAGE, 1970).

\begin{tabular}{lc}
\hline Estado de sanidade & Índice de deterioração \\
\hline Sadio, nenhum ataque & 100 \\
Ataque leve ou superficial de fungos ou térmitas & 90 \\
Ataque evidente mas moderado de fungos ou térmitas & 70 \\
Apodrecimento intenso ou ataque interno de térmitas & 40 \\
Quebra; perda quase total de resistência & 0 \\
\hline
\end{tabular}

\section{RESULTADOS E DISCUSSÃO}

O experimento foi instalado no dia 18 de agosto de 2004. Foram realizadas quatro coletas de sub-amostras, iniciadas a partir do primeiro registro de ataque de coleobrocas nas toras, em 10 de setembro de 2004, quando constatou-se que apenas as peças oriundas das toras de ingá e do campo de apodrecimento de dentro da mata tinham sido infestadas por insetos. Já para as demais sub-amostras, não foi registrada a presença de infestação. Esse fato pode ser explicado por diversos fatores, dentre os quais 
as características químicas da madeira em questão, ou seja, compostos voláteis peculiares a essa espécie poderiam estar atuando na atratibilidade dessa madeira sobre os insetos.

A equipe do prof. Dr. Carlos A. H. Flechtmanm, da faculdade de Engenharia da Unesp de Ilha Solteira, que fez a identificação taxonômica dos insetos coletados, identificou duas espécies da família Platypodidae que ocorreram na madeira de ingá: Euplatypus parallelus (FABRICIUS, 1801) e Teloplatypus ratzeburgi (Chapuis).

Segundo Abreu (1992), a espécie E. parallelus é considerada de importância, principalmente nos trópicos, onde sua distribuição é mais regular. Wolcott, citado por Abreu (1992), relata que é a espécie continental, dentre os Platipodidae, mais largamente distribuída, indo desde a baixa Califórnia até a Argentina, além de ser a mais abundante em Porto Rico.

De acordo com Schedl (1960), existem diversos registros dessa espécie atacando Theobroma cacao L. Abreu e Bandeira (1992) concluíram que E. parallelus é, entre as espécies de besouros da ambrósia, uma das mais abundantes na Amazônia central brasileira.

Ho (1993) relata que E. parallelus é o coleóptero mais comumente encontrado pelo Instituto de Pesquisa Florestal da Malásia atacando árvores injuriadas e madeiras recém-abatidas. O mesmo autor afirma que, embora a atividade dos besouros cesse uma vez que a madeira está seca, o efeito de sua ação pode resultar em severas perdas econômicas, pois a rede de galerias reduz a qualidade e o valor da madeira, bem como dos laminados produzidos com ela.

A ocorrência desses insetos apenas no campo de dentro da mata pode ser explicada por questões relacionadas à umidade relativa do ar e das toras. Em Platypodidae e Scolytidae, o hábito da revoada é estreitamente relacionado com a umidade do ar, ocorrendo preferencialmente no amanhecer e no entardecer, períodos com umidade relativa mais elevada. Dentro de um ambiente florestal, sabe-se que a umidade relativa é superior e mais estável quando comparada com um ambiente sem vegetação, favorecendo, portanto, a atuação desse grupo de insetos.

As temperaturas médias, máxima e mínima, de agosto de 2004 a agosto de 2005, do campo de apodrecimento de dentro da mata, foram de 27 e $20^{\circ} \mathrm{C}$, respectivamente, e as de fora da mata foram de 32 e $20^{\circ} \mathrm{C}$, respectivamente. Para o primeiro campo, ocorreu uma amplitude menor nos valores registrados; para o segundo, foi registrada uma amplitude maior. Esta característica afeta a umidade relativa do ambiente e das toras, favorecendo, desse modo, que sejam estabelecidos teores de umidade, tanto do ar quanto das toras, adequados ao desenvolvimento dos fungos simbiontes, utilizados como alimento pelos insetos.

Oitenta por cento das toras de cinamomo do campo de apodrecimento de dentro da mata apresentaram reação fisiológica, ou seja, emitiram brotações depois de 3 semanas após a montagem dos experimentos, que perduraram por mais 5 semanas após seu registro. Essa observação torna-se importante para o estudo da ocorrência de coleobrocas. Esses insetos são atraídos por compostos emitidos por reações químicas desencadeadas no processo da degradação da madeira. Tais reações liberam etanol, oriundo da fermentação dos extrativos, sendo o atrativo que indica que a madeira apresenta boas condições para o desenvolvimento do fungo simbionte e conseqüentemente do inseto. Estando a madeira fisiologicamente ativa, essa degradação é comprometida, logo, as reações químicas desencadeadas por esse processo também, afetando dessa forma a atração da madeira aos insetos.

Ainda sobre o ataque de insetos nessa espécie, Schanutterer, National Research Council, Huang, citados por Salle; Rech (1999), relatam que ela contém cerca de quatro compostos ativos, dos quais azadiractina, salanina, meliantriol e nimbim são os principais, possuindo comprovada ação inseticida. Comumente, esses compostos são estudados nas folhas e frutos. Ainda não se sabe se eles ou outros atuam como repelentes de insetos no lenho dessa espécie, tornando-a mais resistente a ataques. Santos (1987) afirma que a madeira dessa espécie não é atacada por cupins.

Os maiores índices de deterioração foram registrados nas madeiras de lanterneira e cinamomo, sendo 88 e 90 para as toras expostas no campo de dentro da mata e 98 e 97 para as toras expostas no campo a céu aberto, respectivamente. As toras de eucalipto apresentaram os menores índices médios de deterioração - 60 para dentro da mata e 70 no campo a céu aberto -, o que denota uma maior deterioração dessa madeira em comparação com as outras avaliadas (Tabelas 2 e 3 ). 
Tabela 2. Índice de deterioração das madeiras, percentagem de amostras com madeira dura, rachaduras longitudinais, ataque e espécies de térmitas incidentes, no campo de apodrecimento de dentro da mata, Seropédica, 2005.

Table 2. Index of deterioration of wood, percentage of samples with hard wood, longitudinal cracks, attack and species of incident termites, in the rotten field from inside of the forest, Seropédica, 2005.

\begin{tabular}{|c|c|c|c|c|c|}
\hline \multirow{2}{*}{ Madeira } & \multirow{2}{*}{ ID } & \multicolumn{2}{|c|}{ Dureza da madeira (\%) } & \multirow{2}{*}{ RL (Presença \%) } & \multirow{2}{*}{$\begin{array}{c}\text { Ataque (\%) e espécie de } \\
\text { térmita }\end{array}$} \\
\hline & & Solo & Parte aérea & & \\
\hline M. azedarach & 90 & 100 & 100 & 0 & $17 \%$ - Nasutitermes minor \\
\hline L. lactescens & 88 & 50 & 100 & 17 & $34 \%$ - Nasutitermes minor \\
\hline I. marginata & 87 & 84 & 100 & 0 & $50 \%$ - Nasutitermes minor \\
\hline P. elliottii & 84 & 84 & 100 & 0 & $\begin{array}{l}83 \% \text { - Nasutitermes minor } \\
\text { Heterotermes longiceps }\end{array}$ \\
\hline E. urophylla & 60 & 0 & 50 & 0 & $\begin{array}{r}100 \% \text { - Nasutitermes minor } \\
\text { Nasutitermes jaraguae }\end{array}$ \\
\hline
\end{tabular}

ID: índice de deterioração; RL: rachaduras longitudinais.

Tabela 3. Índice de deterioração das madeiras, percentagem de amostras com madeira dura, rachaduras longitudinais, ataque e espécies de térmitas incidentes, no campo de apodrecimento a céu aberto, Seropédica, 2005.

Table 3. Index of deterioration of wood, percentage of samples with hard wood, longitudinal cracks, attack and species of incident termites, in the rotten field to out of the forest, Seropédica, 2005.

\begin{tabular}{|c|c|c|c|c|c|}
\hline \multirow{2}{*}{ Madeira } & \multirow{2}{*}{ ID } & \multicolumn{2}{|c|}{ Dureza da madeira (\%) } & \multirow{2}{*}{ RL (Presença \%) } & \multirow{2}{*}{$\begin{array}{l}\text { Ataque (\%) e espécie de } \\
\text { térmita }\end{array}$} \\
\hline & & Solo & Parte aérea & & \\
\hline M. azedarach & 97 & 100 & 100 & 100 & 0 \\
\hline L. lactescens & 98 & 100 & 100 & 100 & 0 \\
\hline I. marginata & 92 & 100 & 100 & 0 & 0 \\
\hline P. elliottii & 82 & 100 & 100 & 33 & $34 \%$ - Heterotermes longiceps \\
\hline E. urophylla & 70 & 0 & 100 & 100 & $66 \%$ - Heterotermes longiceps \\
\hline
\end{tabular}

ID: Índice de deterioração; RL: Rachaduras longitudinais.

Um percentual de $50 \%$ das toras de eucalipto, do campo de apodrecimento de dentro da mata, apresentou madeira de consistência mole na parte aérea. Já as demais demonstraram-se duras nesse ambiente (Tabela 2). Na parte enterrada, apenas cinamomo apresentou $100 \%$ da madeira com consistência dura. Ingá e pinus tiveram $84 \%$ de suas toras com madeira dura, na parte subterrânea, lanterneira $50 \%$ e eucalipto $0 \%$, no campo de dentro da mata (Tabela 2). No campo de apodrecimento de fora da mata, quase todas as madeiras apresentaram consistência dura, tanto na parte aérea como na subterrânea, com exceção das toras de eucalipto, que originaram registros percentuais de $0 \%$ de madeira dura na parte subterrânea (Tabela 3).

Relativamente à presença de rachaduras longitudinais, o ambiente do campo de apodrecimento de fora da mata foi mais propício para a ocorrência desse evento nas toras: cinamomo, lanterneira e eucalipto tiveram $100 \%$ de suas amostras com presença significativa dessas rachaduras (Tabela 3). Já no campo de apodrecimento de dentro da mata, apenas $17 \%$ das toras de lanterneira tiveram registros de rachaduras. Para as demais não foi registrado esse fato (Tabela 2). Esse comportamento diferenciado entre os campos de apodrecimento pode ser explicado pela diferença de umidade entre os ambientes, sendo o de dentro da mata mais úmido que o de fora. Neste último, a variação de temperatura foi maior, devido à exposição solar, o que ocasionou processos mais bruscos de secagem e umedecimento, nesse caso, propiciando o surgimento de tensões que levam à ruptura da madeira quando superiores à resistência dos tecidos lenhosos (GALVÃO; JANKOWSKY, 1988).

Foram registrados $57 \%$ das toras do campo de dentro da mata com ocorrência de térmitas, sendo, desse total, 47\% da espécie Nasutitermes minor (HOLMGREN, 1906), 7\% de Nasutitermes jaraguae (HOLMGREN, 1910) e 3\% de Heterotermes longiceps (SNYDER, 1924). As toras de eucalipto foram as mais atacadas, com $100 \%$ das amostras infestadas, sendo seguidas por Pinus (83\%), ingá (50\%), lanterneira 
(34\%) e cinamomo (17\%). A espécie $N$. minor ocorreu em todas as espécies de madeira, sendo que em pinus, além dela, foi registrada H. longiceps, e em eucalipto, ocorreu também N. jaraguae (Tabela 2).

Embora seja conhecido que a madeira de pinus apresenta baixa durabilidade, foi registrado que as amostras da madeira de eucalipto apresentaram-se mais atacadas comparando-se com as de pinus. Isso provavelmente pode ser explicado pela idade da árvore de que foi coletada a madeira, 7 anos para eucalipto e 11 anos para pinus, e pela baixa resistência a térmitas dessa espécie de eucalipto.

Paes; Vital (2000), estudando a resistência natural da madeira de cinco espécies de eucalipto a cupins subterrâneos em testes de laboratório, concluíram que E. urophylla foi a espécie que apresentou menor resistência entre as avaliadas, para as posições internas no tronco.

Silva et al. (2004), ao avaliarem a influência da idade na resistência natural da madeira de Eucalyptus grandis Maiden ao ataque de cupim de madeira seca, Cryptotermes brevis (WALKER, 1953), demonstraram que, quanto mais jovem a madeira, maior é a suscetibilidade ao ataque do cupim, e que a madeira de 10 anos, a mais jovem entre as avaliadas, não apresentou diferença significativa no desgaste feito pelas térmitas quando comparada com a testemunha, Pinus elliottii.

Nas toras do campo de apodrecimento a céu aberto, foi observada a presença de térmitas em $20 \%$ das amostras, todas da espécie $H$. longiceps. As térmitas ocorreram apenas nas toras de eucalipto e pinus, no primeiro caso com $66 \%$ das amostras infestadas, e no segundo, com $34 \%$ (Tabela 3 ). O registro de uma única espécie de térmita no campo de apodrecimento a céu aberto pode sugerir que ela seja mais adaptada às condições desse ambiente, ou seja, a variações de temperatura superiores, umidade inferior, insolação superior, quando comparadas com as condições do campo de apodrecimento de dentro da mata.

Trevisan et al. (2007), ao estudarem a redução de algumas propriedades físicas e mecânicas nessas mesmas madeiras e ambientes, concluíram que as condições diferenciadas de exposição ambiental influenciaram no percentual de redução dessas características. As madeiras provindas do campo de apodrecimento localizado dentro da mata foram as que apresentaram maior redução nessas propriedades, em comparação com as oriundas do campo a céu aberto. As maiores reduções no módulo de elasticidade e na flexão estática foram registradas pelas madeiras das espécies $E$. urophylla e $P$. elliottii, nos dois campos de apodrecimento, sendo que, para o de dentro da mata, a redução foi da ordem de 38 e $35 \%$, e para o campo de fora da mata, 20 e $21 \%$, respectivamente. No módulo de ruptura, os maiores registros de redução percentual também foram obtidos nos ensaios com a madeira dessas espécies, sendo que nas provindas do campo de dentro da mata a redução foi de 52 e $49 \%$, e nas de fora da mata, 20 e $19 \%$, respectivamente.

Esses dados corroboram os resultados deste trabalho, uma vez que as madeiras que se apresentaram mais degradadas, dado expresso pelo índice de deterioração e pela percentagem de ataque de térmitas, também foram as de eucalipto e pinus.

\section{CONCLUSÕES}

- O ambiente influenciou a ocorrência de térmitas e coleobrocas, bem como a degradação das toras.

- O ambiente dentro da mata propiciou uma maior ocorrência de espécies de térmitas, bem como de coleobrocas.

- O ambiente florestal foi mais propício para a deterioração de madeiras, em relação ao ambiente a céu aberto.

- A madeira de Inga marginata foi susceptível ao ataque da espécie Euplatypus parallelus e Teloplatypus ratzeburgi (Coleoptera: Platypodidae).

- As toras de Melia azedarach e Lophantera lactescens foram as menos deterioradas nos dois ambientes.

- As toras de Eucalyptus urophylla foram as mais deterioradas nos dois ambientes.

- O ambiente a céu aberto propiciou, de forma superior, o aparecimento de rachaduras nas toras, em comparação com o ambiente de dentro da mata.

- No campo dentro da mata, Nasutitermes minor ocorreu em todas as espécies de madeira. Em Pinus elliottii, além desta, ocorreu também Heterotermes longiceps, e em Eucalyptus urophylla, ocorreu também Nasutitermes jaraguae.

- No campo de apodrecimento a céu aberto, ocorreu apenas Heterotermes longiceps nas toras de Eucalyptus urophylla e Pinus elliottii. 


\section{AGRADECIMENTOS}

À Capes (Coordenação de Aperfeiçoamento de Pessoal de Nível Superior), pela concessão de uma bolsa de estudos para o primeiro autor. Ao prof. Dr. Carlos A. H. Flechtmanm, pela identificação das coleobrocas. Ao prof. Dr. Reginaldo Constantino, pela identificação dos térmitas.

\section{REFERÊNCIAS}

ABREU, R. L. S., Estudo da ocorrência de Scolytidae e Platypodidae em madeiras da Amazônia. Acta Amazônica, Manaus, v. 3, p. 413-420, 1992.

APRILE, F. M.; DELITTI, W. B. C.; BIANCHINI JR., L. Aspectos cinéticos da degradação de laminados de madeira em ambientes aquático e terrestre. Revista Brasileira de Biologia, Rio de Janeiro, v. 59, n. 3, p. 485-492, 1999.

CAVAlCANTE, M. S. Métodos para aumentar a durabilidade da madeira. Boletim da Associação Brasileira de Preservadores de Madeira, São Paulo, n. 36, p. 159-170, 1985.

FURNISS, R. L.; CAROLIN. V. M. Western forest insects. Washington, DC: USDA, 1977. 654 p.

GALVÃO, A. P. M.; JANKOWSKY, I. P. Secagem racional da madeira. São Paulo: Nobel, 1988. 112 p.

HO, Y. F. Platypus parallelus, a common ambrosia beetle of timbers. Technical-Information Forest Research Institute Malaysia, Malásia, v. 43, p. 4, 1993.

LEPAGE, E. S. Método Sugerido pela IUFRO para ensaios de campo com estacas de madeira. Preservação de madeiras, São Paulo, v. 1, p. 205-216, 1970.

LOPEZ, G. A.; MILANO, S. Avaliação da durabilidade natural da madeira e de produtos usados na sua proteção. Manual de preservação de madeiras. São Paulo: Instituto de Pesquisas Tecnológicas do Estado de São Paulo. 1986. v.2. p. 473-510.

MATOSKI, S. L. S.; ROCHA, M. P. da. Influência do fotoperíodo no ataque de dinoderus minutus fabricius (coleoptera: bostrichidae) em lâminas torneadas de espécies tropicais. Floresta, Curitiba, v. 36, n. 3, set./dez. 2006.

OLIVEIRA, A. M. F.; LELIS, A. T.; LEPAGE, E. S.; CARBALLERA LOPEZ, G .A.; OLIVEIRA, L. C. S.; CANEDO, M. D.; MILANO, S. Agentes destruidores da madeira. In: LEPAGE, E. S. (Coord.) Manual de preservação de madeiras. São Paulo: IPT, 1986. v. 1. p. 99-279.

PAES, J. B.; VITAL, B. R.; ARAÚJO, G. T. Mecanismos de decomposição da madeira por fungos. Tecbahia: Revista Baiana de Tecnologia, Camaçari, v. 16, n. 2, p. 128-136, 2001.

PAES, J. B.; VITAL, B. R. Resistência natural da madeira de cinco espécies de eucalipto a cupins subterrâneos, em teste de laboratório. Revista Árvore, Viçosa, MG, v. 24, n. ??, p. 97-104, 2000.

RICHARDSON, B. A. Wood preservation. 2. ed. London: E \& FN SPON, 1993. 226p.

SALLES, L. A.; RECH, N. L. Efeito de extratos de nim ( Azadiractha indica) e cinamomo (Melia azedarach) sobre Anastrepha fraterculus (WIED.) (DIPTERA:TEPHRITIDAE). Revista Brasileira de Agrociência, Pelotas, v. 5, n. 3, p. 225-227, 1999.

SANTOS, E. Nossas madeiras. Belo Horizonte: Itatiaia, 1987. 313p.

SCHEDL, K. E. Bark and timber beetles from the neotropical region. 173 contribution to the morphology and taxonomy. Col. Bull., [S.1.], v.14, p. 74-80, 1960.

SGAI, D. R. Fatores que afetam o tratamento para preservação de madeiras. 100 f. Dissertação (Mestrado em Engenharia Civil) - Setor de Engenharia, Universidade Estadual de Campinas, Campinas 2000. 
SILVA, J. C.; CABAlleIRA LOPEZ, A. G.; OLIVEIRA, J. T. S. Influência da idade na resistência natural da madeira de Eucalyptus grandis W. Hill ex. Maiden ao ataque de cupim de madeira seca (Cryptotermes brevis). Revista Árvore, Viçosa, MG, v. 28, n. 4, p. 583-587, 2004.

SIMEONE, J. B. Insects and wood. New York: Syracuse, 1965. 178 p.

SWIFT, M. J.; HEAL, D. W.; ANDERSON, J. M. Studies in Ecology-Decomposition in Terrestrial and Aquatic Ecosystems. Oxford: Blackwell, 1979.

TREVISAN, H.; DE NADAI, J.; LUNZ, A. M.; CARVALHO, A. G. Ocorrência de térmitas subterrâneos (isoptera: rhinotermitidae e termitidae) e durabilidade natural da madeira de cinco espécies florestais. Ciência Florestal, Santa Maria, RS, v. 13, n. 2,. p. 153-158, 2003.

TREVISAN, H.; CARVALHO, A, G.; TIEPPO, F, M, M.; LELIS, R. C. C. Avaliação de propriedades físicas e mecânicas da madeira de cinco espécies florestais em função da deterioração em dois ambientes. Revista Árvore, Viçosa, MG, v. 31, p. 30-37, 2007. 